Project Accomplishment Summary For

Project Number 92-MULT-015-B2-04

\title{
PREDICTIVE MODEL AND METHODOLOGY FOR HEAT TREATMENT DISTORTION
}

\author{
Gerard M. Ludtka \\ Lockheed Martin Energy Research \\ Ms. Tracy Pattok \\ National Center for Manufacturing Sciences \\ Dr. William E. Dowling, Jr. \\ Ford Motor Company \\ Ronald Leachman \\ General Motors Corporation \\ Harry Walton \\ Torrington Company
}

February 17, 1998

\author{
Prepared by the \\ Oak Ridge Y-12 Plant \\ managed by \\ LOCKHEED MARTIN ENERGY SYSTEMS, INC. \\ for the \\ U.S. DEPARTMENT OF ENERGY \\ under contract DE-AC05-84OR21400
}




\section{DISCLAIMER}

This report was prepared as an account of work sponsored by an agency of the United States Government. Neither the United States Government nor any agency thereof, nor any of their employees, makes any warranty, express or implied, or assumes any legal liability or responsibility for the accuracy, completeness, or usefulness of any information, apparatus, product, or process disclosed, or represents that its use would not infringe privately owned rights. Reference herein to any specific commercial product, process, or service by trade name, trademark, manufacturer, or otherwise, does not necessarily constitute or imply its endorsement, recommendation, or favoring by the United States Government or any agency thereof. The views and opinions of authors expressed herein do not necessarily state or reflect those of the United States Government or any agency thereof. 


\section{PROJECT ACCOMPLISHMENT SUMMARY}

Title: $\quad$ Predictive Model and Methodology for Heat Treatment Distortion

DOE TTI Number: 92MULT015-B2-04

CRADA Number PES002-0077

Partner: National Center for Manufacturing Sciences (NCMS)

\section{BACKGROUND}

In manufacturing industries, companies devote time and resources to dealing with the unanticipated effects of heat treatment, in particular distortion. The resource cost of distortion begins with the design process. An initial design requires revisions because unpredictable changes occur in shape of performance of a component when it is heat treated. The result is often successive design iterations or a substantial redesign of the component with lost time and lengthened time to market. Additional cost is associated with the need to provide finishing operations for a heat-treated component. Finishing restores the shape of a component or removes unwanted material deliberately left on a component in anticipation of distortion. This need results in higher capital equipment and piece costs for products. Finally, a percentage of manufactured parts must be scrapped when distortion exceeds acceptable levels.

Wasted time and resources are a direct loss to the manufacture - the cost of which is ultimately passed on to the customer. This would be reduced significantly if component response to heat treatment could be predicted. At the initiation of this CRADA, the automotive industry participants (General Motors and Ford) stated that no successful predictive tool existed that would facilitate the prediction of material response to heat treatment. The development of a methodology and a predictive tool to facilitate accurate predictions of heat treatment distortion, residual stress, and microstructure in an automotive transmission gear was the goal of this research program.

Although the goal of this project was centered upon the heat treatment distortion, residual stress, and microstructure of automotive transmission gears, the same issues are inherent in the heat treating of any production item including weapons components. Algorithms developed to predict the effects of heating of transmission gears would be able to be adapted to weapons components. Thus reducing machining time and waste.

\section{DESCRIPTION}

The purpose of this project was to develop a modeling methodology and software tool to simulate and predict the results of heat treatment, especially distortion. In order to develop a simulation tool, significant technical, analytical, and experimental resources were needed. This task was too large and complex for just one company or organization to address. To this end, 4 national laboratories (Los Alamos National Laboratory, Lawrence Livermore National Laboratory, the Oak Ridge National Laboratory/Y-12 Plant, and Sandia National Laboratories and many partners working through NCMS tackled this effort. The participants through NCMS were Ford Motor Company, General Motors Corporation, The Torrington Company, Deformation Control 
Technologies, The MacNeal-Schwindler Corp. IIT Research Institute, the Gear Research Institute, U.S. Benet Laboratories (Army), and the Colorado School of Mines. For the purpose of this report only those items pertinent to the Oak Ridge National Laboratory/Y-12 Plant participation in this CRADA will be highlighted along with those related items directly related to these specific efforts that were accomplished by the partners.

The Oak Ridge National Laboratory/Y-12 research responsibilities for this CRADA included 4 main project areas. These included: Materials Characterization, Constitutive Relations, Finite Element Analysis, and Residual Stress Measurement. The Materials Characterization task involved the characterization of the phase transformation kinetic (dilatometry) behavior of the alloys of interest to the CRADA in addition to the determination of the mechanical behavior and thermalphysical properties of these alloys as a function of temperature and microstructure. The Constitutive Relations task involved working with the other CRADA participants to develop a material response model for incorporation into the predictive tool that handled all relevant material response behaviors pertinent to residual stress, distortion, and microstructure evolution predictions for the automotive carburizing quenching application. Demonstration of the tool by running a computer simulation analyses for a specific application was the goal of the Finite Element Analysis task of this project. The final task category of Residual Stress Measurements involved the evaluation of neutron diffraction techniques for measuring residual stresses in quenched automotive gears.

The industrial participants provided technical support and relevant materials and test specimens for the activities described above. Literally, several hundred mechanical property tensile and compression test specimens were provided for the Contractor. Also, several hundred dilatometer test samples were produced to facilitate the phase transformation kinetic response characterization efforts of the Contractor. Specialty alloy heats were fabricated through the NCMS members to facilitate the Contractor's characterization efforts during the entire duration of this CRADA. Precision machined gears and blanks were provided through NCMS for the residual stress measurement by the neutron diffraction technique evaluation study.

Based on test data from the mechanical property tensile and comparison test specimens outlined above, algorithms were developed to simulate the effects of heat treating. This effort is still on going although the DOE/DP funding was withdrawn from the project. The simulation process that has been developed has been successfully demonstrated on the automotive components as well as on uranium and plutonium alloys.

\section{BENEFITS TO DOE}

The development of this predictive tool is extremely beneficial to Defense Programs R\&D goals in that it enable the ability to predict weapons materials performance in several areas. First, this tool will enable significant advances to be made in intelligent manufacturing and rapid prototyping of uranium and plutonium alloy components. The economic and recycling advantage is significant if new designs for weapons systems can be optimized prior to manufacturing. Second, the broad simulation capability of the predictive tool will enable stress-induced phase transformations to be modeled which is particularly relevant to $\mathrm{U}-6 \mathrm{Nb}$ alloy system which undergoes thermalelastic 
martensite transformations and stress-assisted preferred variant martensite formation. Prediction of the response to heat treatment of the very complex plutonium alloy transformation behavior will benefit significantly through the simulation capabilities of this predictive tool. Third, customization of this tool will enable prediction of material behavior in stockpile "aging" to be simulated for handling alloy phase stability and interface degradation analyses. Since enriched uranium and plutonium alloys are extremely expensive in light of their initial refining costs plus the high cost to handle and recycle machined scrap, the ability to evaluate a new design for manufacturability and performance prior to actual fabrication efforts will dramatically reduce prototype weapon fabrication cost and implementation time.

\section{ECONOMIC IMPACT}

The successful implementation of this predictive tool has the potential for significant economic impact on U.S. industries dependent on heat treatment of steels in their manufacturing process. In a letter dated 9/5/97 from Ralph Larson, principal metallurgist for EATON at the time, to Gerard Ludtka, CRADA PI at ORNL, Larson states that he expects no less than a $\$ 10 \mathrm{M} / \mathrm{yr}$. impact for Eaton Truck Components Operations - North America when this tool is fully deployed at the end of Phase II. In this same letter, Larson projects a potential savings across all North American industries would be expected to exceed $\$ 10 \mathrm{~B} / \mathrm{yr}$ in terms of improvements. Secondary benefits were also cited which include: reduced energy consumption, reduced material scrap, improved time to market and speed of design, and improved meeting of design intent to mission. These economic advantages will result in improved competitiveness for U.S. industries in the global marketplace. Similarly, the U.S. consumer would be expected to pay less for commodities manufactured using the predictive tool during their design and process optimization stage as a result of reduced design and product implementation efforts and costs plus reduced scrap resulting in improved material efficiency. These advantages and benefits were those which were cited in the initial CRADA document as justification for conducting this research and development effort. Finally, the consumer taxpayer would see the benefit in reduced weapons system costs once this methodology and predictive tool are implemented by Defense Programs. Developments of this project have been utilized by the Defense Labs in support of their weapons programs already.

\section{PROJECT STATU}

This project is in its second three-year development effort designated as PHASE II. This report covers PHASE I goals. Phase II is directed at broadening the scope to other industries, applications, and alloys beyond the focused automotive transmission gear problem selected for PHASE I. PHASE I was successful in demonstrating that a methodology for simulating heat treatment distortion for the carburizing and quenching process was developed. PHASE I funding came through the DOE DP Program Office. In Jan.'97, PHASE II was initiated with funding support through the DOE EE OTT Lightweight Materials PNGV Program.

\section{DOE FACILITY POINT OF CONTACT FOR PROJECT INFORMATION:}

The principal investigator for this effort and author of this Project Accomplishment Statement is: Gerard M. Ludtka, Ph.D.

Senior Development Staff Member II 
Metals \& Ceramics Division

Oak Ridge National Laboratory

P. O. Box 2008

Bldg. 4500-S, MS-6155, Room B-64

Oak Ridge, TN 37831-6155

Voice: 423-574-5098

FAX: 423-574-5118

Email: gmz@ornl.gov

\section{COMPANY SIZE AND POINTS OF CONTACT:}

Although NCMS was the formal participant in Phase I of this CRADA, they represented three major industrial partners who contributed to the success of this program. These include General Motors, Ford, and Torrington Bearing. The two automotive companies have made record sales and profit this past year and employ a significant segment of the U. S. workforce. Torrington is a major supplier of bearing components to the automotive and other industries and has a large workforce also. The principal contacts who were the principal investigators for these companies in Phase I are:

Dr. William E. Dowling, Jr.

Ford Motor Company

Manufacturing Systems Dept.

P.O.Box 2053/MD 3135

Room 2022a SRL

Dearborn, MI 48121-2053

Voice: $313-337-4149$

FAX: 313-390-0514

Mr. Ronald Leachman

General Motors Corporation

GM Powertrain

Ecorse \& Wiard Roads

Ypsilanti, MI 48198

Voice: $313-481-5380$

FAX: 313-481-5192

Mr. Harry Walton

The Torrington Company

Shiloh Plant

221 South

Box T

Rutherfordton, NC 28139

Voice: 704-287-2200, x289

FAX; 704-286-8929 
Ms. Tracy Pattok

Program Manager

National Center for Manufacturing Sciences

3025 Boardwalk

Ann Arbor, MI 48108

Voice: 734-995-4926

FAX: 734-995-1150

\section{PROJECT EXAMPLES}

The Phase I Summary report has been issued by NCMS for Phase I of this project. It provides examples of the application of this predictive tool to a gear and gear blank for the purpose of predicting distortion, residual stress, and microstructure in these shapes. Significant enhancements to the predictive tool have already been implemented through the follow-on Phase II effort. The summary report can be obtained from NCMS if required.

\section{TECHNOLOGY COMMERCIALIZATION}

NCMS with the agreement of all industrial participants has procured the services of Deformation Control Technologies (DCT) to be the System Integrator responsible for development of the commercial version of the predictive tool by the end of PHASE II (9/99). Currently, this predictive tool is protected as Proprietary Information via the CRADA agreement for the industrial participants for a period of 18 months beyond the completion of this program. In the meantime, DCT will maintain updates to this software product and provide training to new industrial users within the project. After the 18 month period, NCMS, through DCT, will market this software to new users for the purpose of optimizing their industrial processes involving heat treatment. NCMS, through the CRADA's Steering Committee, is currently evaluating existing licensing strategies within the software industry to determine a fair market price to charge new users for licenses to obtain the predictive tool for their own applications. 


\section{Distribution:}

Gerard Ludtka, MS 6155, 4500S

Joyce Shepherd, MS 6416, 5002

Ray Ford, MS 8084, 9203

Diane Bird, DOE DP-17

Brian Hooper, DOE DP-17

Bill Wilburn, MS 8015, 9704-2

Lab Records, MS 6285, 4500N

Y-12 Central Files, MS 8169, 9711-5 (3 copies)

Dr. William E. Dowling, Jr., Ford Motor Company, Manufacturing Systems Dept., P.O. Box 2053/MD 3135, Room 2022a SRL, Dearborn, MI 48121-2053 (5 copies)

Mr. Ronald Leachman, General Motors Corporation, GM Powertrain, Ecorse \& Wiard Roads, Ypsilanti, MI 48198 (5 copies)

Mr. Harry Walton, The Torrington Company, Shiloh Plant, 221 South, Box T, Rutherfordton, NC 28139 (5 copies)

Ms. Tracy Pattok, Program Manager, National Center for Manufacturing Sciences, 3025

Boardwalk, Ann Arbor, MI 48108 (5 copies) 